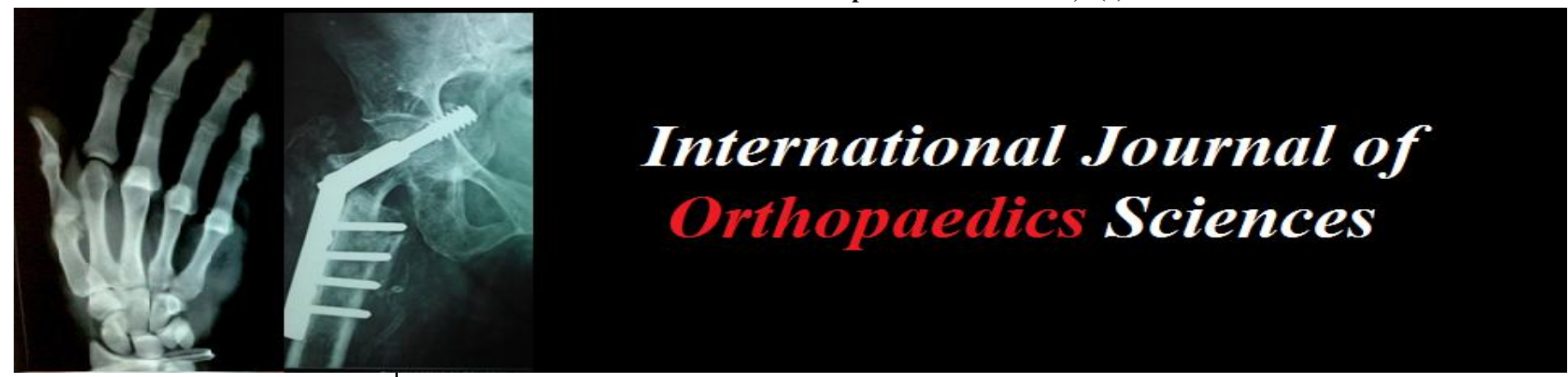

ISSN: $2395-1958$

IJOS 2018; 4(1): 05-11

(C) 2018 IJOS

www.orthopaper.com

Received: 02-11-2017

Accepted: 03-12-2017

Dr. Raja Rathnam Korani MS, Orthopaedics, Civil Surgeon Specialist, District Head

Quarters Hospital, Tandur,

Vikarabad, Telangana, India

\section{Monteggia fracture dislocation: A study on the functional outcome of surgical treatment in patients attending Osmania General Hospital, Hyderabad, Telangana, India}

\section{Dr. Raja Rathnam Korani}

\section{DOI: https://doi.org/10.22271/ortho.2018.v4.i1a.02}

\begin{abstract}
The aim of this study was to assess the effectiveness of surgical treatment by open reduction and internal fixation of Monteggia fracture dislocation and evaluate the union of fracture, complications encountered during treatment and assess the functional outcome of the results. The study comprised of 18 cases including adults and children, admitted in orthopaedic wards of Osmania General Hospital, Hyderabad, Telangana, India. The patients age range was $7->50$ yrs. The incidence of injury was of Type I in $77.77 \%$ and Type II $22.23 \%$ cases, no cases of type III and Type IV fracture dislocation and children had only Type I fracture dislocation. The acute cases were treated surgically, using medullary nails, plate fixation and lag screw as implants. Open reduction was done in $77.73 \%$ and closed reduction in $22.22 \%$ cases. Regular follow up was done between 4 to 8 weeks duration and all fractures healed satisfactorily. The functional outcome of the results were evaluated using Anderson's scoring system and graded as excellent / good, fair and poor depending on the range of motion in flexion-extension and pronationsupination. Our study results were excellent/good in $46.15 \%$ cases, fair and satisfactory in $7.69 \%$ and bad results in $46.15 \%$ patients. The functional outcome of surgical treatment in fresh cases of our study was good in $62.50 \%$ cases, fair in $12.5 \%$ and bad results in $25 \%$ patients. Out 3 cases of conservative treatment, 1 case showed good results and 2 cases bad results were observed in $n=2(67 \%)$ cases. In this study, 2 old cases treated surgically showed bad results.
\end{abstract}

Keywords: monteggia fracture, radial head dislocation, ulna fracture

\section{Introduction}

A fracture of the proximal ulna associated with an anterior dislocation of the radial head 1 was first described by an Italian surgeon, Giovanni Battista Monteggia ${ }^{[1]}$. This injury pattern was eponymously named as the Monteggia fracture-dislocation (MFD) by Perrin ${ }^{[2]}$.

The Monteggia lesion is a typical example of a double bone injury, characterized by a radial dislocation and a fracture of the ulna. 'Monteggia lesion' is a group of traumatic lesions having in common dislocation of the radio-humero-ulnar joint, associated with a fracture of ulna at various levels or with lesions at the wrist. This concept is different from that described by Monteggia ${ }^{[1]}$, which represents only one type.

Bado preferred the term 'monteggia lesion' and classified these injuries into 2 categories: 'Monteggia lesion' and 'Monteggia equivalents' based on the mechanism of the injury and the direction of the dislocation ${ }^{[3]}$.

Bado ${ }^{[3]}$ classified monteggia lesions into four (Fig. 1) distinct categories:

Type-I (Extension injury) is a fracture of ulnar diaphysis at upper third level with anterior angulation at the fracture site and an associated anterior dislocation of the radial head (60\% of the cases).

Type-II (Flexion injury) is a fracture of ulnar diaphysis with posterior angulation at the fracture site and a posterior or postero-lateral dislocation of radial head (15\% of the cases).

Type-III is a fracture of ulnar metaphysis with lateral or antero-lateral dislocation of radial head $(20 \%$ of the cases).

Type-IV is a fracture of the proximal third of radius and ulna at the same level with anterior

\section{Dr. Raja Rathnam Korani} MS, Orthopaedics, Civil Surgeon Specialist, District Head Quarters Hospital, Tandur, Vikarabad, Telangana, India 
dislocation of radial head.

Type-I lesion is the most common, Type-III and type-II lesions are next in the frequency and Type-IV lesions are the rarest.

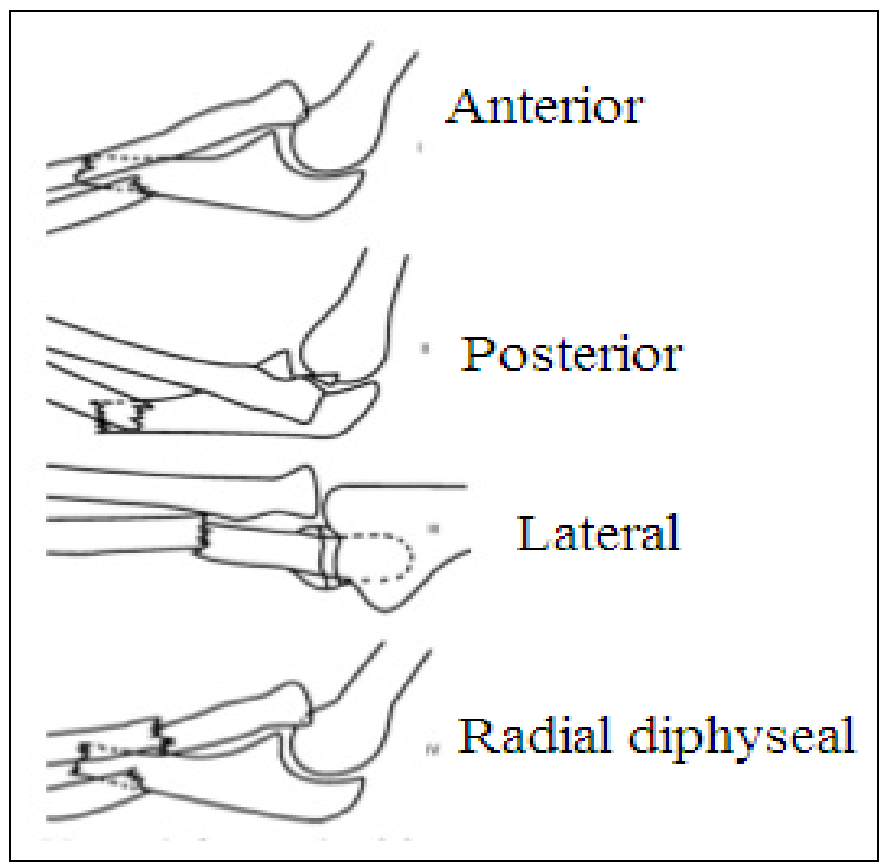

Fig 1: Bado's classification of monteggia fracture dislocation

Monteggia fractures are more commonly seen in adults but they are well described in children. These injuries are relatively uncommon, accounting to less than 5\% of all forearm fractures ${ }^{[4]}$. It is inherently unstable due to variety of factors which are poorly understood by many surgeons. Mistakes in their management account for high incidence of poor results. Until 1940, the overall results of treatment were abysmal. In a series of 34 Monteggia lesions treated by many surgeons, there were only two good results, and 32 out of 34 had serious permanent disabilities".

The interesting mechanism of injury and unstable nature of the lesion and also the usual poor outcome of the results prompted us to undertake this study, not a common fracture dislocation, for a better understanding and management. Therefore, the aim of the present study was to evaluate the effectiveness of surgical treatment by open reduction and internal fixation of Monteggia fracture dislocation, assess the union of fracture, complications encountered during treatment and assess the functional outcome of the results.

\section{Material and Methods}

The present study was conducted in the Department of Orthopaedics, Osmania Medical College, Hyderabad, Telangana, India. The patients with closed fracture of shaft of ulna with dislocation of proximal radio-ulnar joint, admitted in orthopaedic wards of Osmania General Hospital, Hyderabad, Telangana, India, were included in this study. During the study period, 18 cases of monteggia fracture dislocation in children and adults were studied.

The inclusion criteria were patients with a fracture of the proximal ulna together with a fracture of the radial head or neck, patients who gave their consent to undergo the procedure, patients presented within 3 weeks after injury. The exclusion criteria included elderly patients, patients with neurovascular deficiency and patients medically unfit for surgery.
Ethical Committee approval was taken from the Institutional Ethical Committee Board. Thorough clinical history was taken from each patient and/or attendants to know the mode of injury and the severity of trauma as well as radiographic data. All patients were examined thoroughly for their general condition, and associated injuries were noted. All the findings were duly recorded in the patient proforma. The written informed consent for surgery was obtained from the patients and they were operated after a pre-anesthetic checkup.

Standard radiographs of antero-posterior and lateral views of the elbow with forearm were taken to assess the dislocation of the radial head for confirmation of the diagnosis and also to know the type of fracture. The classifying of fractures was done by analyzing location, displacement and angulation of ulna and/or radius fracture dislocation according to Bado's ${ }^{[3]}$ classification system.

A total of $n=18$ patients were identified with Monteggia lesions comprising of $n=15$ male and $n=3$ female cases. 17 patients were available for follow-up which included $n=4$ under follow-up and $n=1$ no follow-up. The patients were between the age group 7 yrs to above 50 yrs. Right extremity was involved in $n=9$ patients and left $n=9$ cases, in the ratio $1: 1$.

The causes of injury included road traffic accident $(n=10)$, fell down while playing $(n=1)$, from bicycle $(n=2)$, from scooter $(n=4)$ and $n=1$ patient was hit with stick and on attempt to protect his head got injured his left forearm.

The functional outcome of the results was done according to Anderson et al. ${ }^{[5]}$ taking the range of movement as the main criteria, after physiotherapy. The results were graded as excellent / good, fair and poor depending on the range of motion in flexion-extension and pronation-supination.

\section{Case description}

Monteggia fracture dislocations are uncommon and in three years $n=18$ cases were studied. The patients were presented within first week to three weeks. The data presented in Table 1 shows the incidence of age distribution of the cases was between 7 yrs - above 50 yrs. Maximum incidence of the injury was seen between the age group $21-30$ yrs in $\mathrm{n}=7$ $(38.88 \%)$ cases, followed by $31-40$ yrs in $n=4(22.22 \%)$, below 10yrs in $\mathrm{n}=3(16.66 \%)$ patients, between the age group $11-20 \mathrm{yrs}$ in $\mathrm{n}=2(11.11 \%)$ cases and above $50 \mathrm{yrs}$ in $\mathrm{n}=2(11.11 \%)$ patients.

Table 1: Distribution of subjects based on the incidence of age in the present study

\begin{tabular}{|c|c|c|c|c|c|c|}
\hline Subjects & $\begin{array}{c}\text { Upto } \\
\text { 10yrs }\end{array}$ & $\begin{array}{c}\mathbf{1 1 - 2 0} \\
\text { yrs }\end{array}$ & $\begin{array}{c}\mathbf{2 1 - 3 0} \\
\text { yrs }\end{array}$ & $\begin{array}{c}\mathbf{3 1 - 4 0} \\
\text { yrs }\end{array}$ & $\begin{array}{c}\mathbf{4 1 - 5 0} \\
\text { yrs }\end{array}$ & $\begin{array}{c}\text { Above } \\
\text { 50 yrs }\end{array}$ \\
\hline $\mathrm{n}=$ & 3 & 2 & 7 & 4 & 1 & 1 \\
\hline $\begin{array}{c}\text { Percentage } \\
(\%)\end{array}$ & 16.66 & 11.11 & 38.88 & 22.22 & 5.55 & 5.55 \\
\hline
\end{tabular}

Male patients were $\mathrm{n}=15(83.33 \%)$ and female patients were only $3(16.67 \%)$, in 5:1 ratio (Table 2) showing male predominance. Right side was involved in $\mathrm{n}=9$ cases and left side in $n=9$ cases. The incidence of injury was of Type I (extension type) in maximum number of cases $\mathrm{n}=14$ $(77.77 \%)$ and $n=4(22.23 \%)$ cases were of Type II (flexion). There were no cases of type III and Type IV fracture dislocation. In this series, children had only Type I fracture dislocation. In our study, $\mathrm{n}=16(88.88 \%)$ cases had simple fracture while, $\mathrm{n}=2(11.12 \%)$ patients had compound fracture. $10(56.55 \%)$ patients sustained injuries as a result of direct injury (bruises, contusions) and $n=8$ (44.45\%) indirect 
(Table 2). 15 patients were presented within 1 week of injury and 3 after one week.

Table 2: Gender, side and type and mode of injury in the present study

\begin{tabular}{|c|c|c|c|c|c|c|c|c|c|c|}
\hline \multirow{2}{*}{ Subjects } & \multicolumn{2}{|c|}{ Gender } & \multicolumn{2}{c|}{ Side } & \multicolumn{2}{c|}{ Type of injury } & \multicolumn{2}{c|}{ Mode of injury } & \multicolumn{2}{c|}{ Clinical type } \\
\cline { 2 - 10 } & $\mathbf{M}$ & $\mathbf{F}$ & $\mathbf{R}$ & $\mathbf{L}$ & Type I & Type I & Direct & Indirect & Simple & Compound \\
\hline $\mathrm{n}=$ & 15 & 3 & 9 & 9 & 14 & 4 & 10 & 8 & 16 & 2 \\
\hline Percentage (\%) & 83.33 & 16.67 & 50 & 50 & 77.77 & 22.23 & 56.55 & 44.45 & 88.88 & 11.12 \\
\hline
\end{tabular}

The level of fracture ulna presented in Table 3, showed maximum incidence occurred at the junction of upper and middle third in $\mathrm{n}=8(44.44 \%)$ cases, followed by proximal third ulna in $n=5(27.79 \%)$, middle third ulna $n=4(22.23 \%)$ and minimum $\mathrm{n}=1(5.55 \%)$ case of olecranon. The patients presented with associated injuries were $\mathrm{n}=5(27.78 \%)$ cases whereas, $\mathrm{n}=13(72.22 \%)$ cases were without associated injuries.

Table 3: Levels of ulnar fracture in Monteggia lesions in the present study

\begin{tabular}{|c|c|c|c|c|}
\hline Subjects & Olecranon & Proximal 3 ${ }^{\text {rd }}$ ulna & Junction of upper \& middle third ulna & Middle 3 $^{\text {rd }}$ ulna \\
\hline $\mathrm{n}=$ & 1 & 5 & 8 & 4 \\
\hline Percentage (\%) & 5.55 & 27.79 & 44.44 & 22.22 \\
\hline
\end{tabular}

The patients were presented with tenderness, pain, bony irregularity, crepitus, swelling, deformity of the forearm at upper and middle third junction, inability to use the upper limb, swelling around the elbow or over radial aspect. Forearm was semi-flexed and in semi-prone position. There was posterior angulation of ulnar border. Swelling of the elbow was more on postero-lateral aspect. Contusion of skin over volar aspect was at the junction of upper with middle third. Radial head was not in its position, dislocation was postero-lateral.
The data on the extension type of injury (Type I) summarized in Table 4 shows the displacement of ulnar fragments were antero-lateral in $\mathrm{n}=5(35.71 \%)$ cases, lateral in $\mathrm{n}=3$ (21.42\%), anterior in $\mathrm{n}=2(14.29 \%)$, overlapping of fragment in $\mathrm{n}=3(21.42 \%)$ cases and overlapping and comminution in $\mathrm{n}=1(7.14 \%)$ case.

The data on the extension type of injury (Type I) with the displacement of radial head (Table 4) was antero-lateral in $\mathrm{n}=$ $9(64.29 \%)$ cases, anterior in $\mathrm{n}=3(21.42 \%)$ cases and lateral in $\mathrm{n}=2(14.29 \%)$ cases.

Table 4: Type of displacement of ulnar / radial fragments in the cases of the present study

\begin{tabular}{|c|c|c|c|c|}
\hline \multirow{2}{*}{$\begin{array}{c}\text { Type of displacement in Type I } \\
\text { injury }\end{array}$} & \multicolumn{2}{|c|}{ Ulnar fragments } & \multicolumn{2}{c|}{ Radial head displacement } \\
\cline { 2 - 5 } & $\mathbf{n}=$ & Percentage (\%) & 9 & Percentage (\%) \\
\hline Anterior-lateral & 5 & 35.71 & 2 & 64.29 \\
\hline Lateral & 3 & 21.42 & 3 & 21.29 \\
\hline Anterior & 2 & 14.29 & - & - \\
\hline Overlapping of fragment & 3 & 21.42 & - & - \\
\hline Overlapping \& comminution & 1 & 7.14 & & - \\
\hline
\end{tabular}

\section{Surgical Management}

For all the patients routine preoperative tests were done. Consent for surgery was obtained. All operations were performed under general anesthesia using tourniquet. First, attempt was made to reduce the dislocation of the radial head by traction on the forearm and counter traction on the arm followed by flexion of the elbow to $110-120^{\circ}$.

Open reduction and internal fixation of ulna by plating was done under general anesthesia (GA) using tourniquet ischemic control. The acute cases were treated surgically which included medullary nails in $\mathrm{n}=4(22.22 \%)$ cases, plate fixation in $\mathrm{n}=5(27.71 \%)$ and lag screw in $\mathrm{n}=4(22.22 \%)$ cases as implants. Open reduction was done in $\mathrm{n}=14$ $(77.73 \%)$ cases and closed reduction in $n=4(22.22 \%)$ cases. Lag screw was used for fractures which were in proximal third and in olecranon. Plate fixation for shaft fractures and medullary nail was used mostly for acute cases, having shaft fractures. Compression plate was not used in any case.

The patients treated conservatively were $n=4(22 \%)$ cases which included a child and those adults with comminuted fractures and compound injuries. Type I fractures which were treated conservatively, were reduced under general anesthesia (GA) by applying traction in the long axis of the fore arm, followed by forced supination and if necessary by direct pressure to relocate the radial head. Immobilization was done in $\mathrm{A} / \mathrm{E}$ casing with more than $90^{\circ}$ flexion at elbow.

Type II cases were immobilized in more than $90^{\circ}$ flexion to reduce the stiffness in extension. Management of dislocated radial head was done by closed reduction method in majority of the patients $n=14(77.77 \%)$. Excision of radial head was done in $\mathrm{n}=4(22.22 \%)$ cases and repair of annular ligament in $\mathrm{n}=1(5.55 \%)$ case.

There were $n=3$ old cases: (1). Malunion with dislocated radial head and associated myositis ossificans. (2). A case of late displacement of radial head in casing following conservative management having malunion of ulna which was accepted and radial head excised. (3). Monteggia fracture treatment got delayed due to infection near the lesion.

\section{Post-operative management and follow up}

The posterior slab and sutures were removed on the $10^{\text {th }}$ day and long arm cast was applied with elbow in flexion and patients were discharged. The cast was removed at four weeks, and the extremity was supported with cuff and collar sling, maintaining the elbow at $110-120^{\circ}$. Regular follow up was done between 4 to 8 weeks duration. All fractures healed satisfactorily. Gentle pronation and supination motions were permitted, but extension was not permitted below $90^{\circ}$ until 6 weeks after injury.

After six weeks of follow up, detailed clinical examination such as tenderness, movements of elbow joint, and power of the muscles acting on the joint were noted. The patient was assessed subjectively for the symptoms like pain and restriction of joint motion. For radiological assessment check 
X-rays of the union of fracture were taken. Physiotherapy was advised after 6 weeks of surgery.

Patients were advised to carry out active exercises at home, like active flexion, extension, pronation and supination without applying load. Later, patients were advised to report for follow up after 8 weeks. Check X-rays were taken for assessment of radiological union.

\section{Evaluation of results}

The patient with clinically no tenderness, no subjective complaints and when the fracture line was not visible radiologically, the fracture was considered united. Fractures were considered as delayed union when healed after 6 months, without an additional procedure of operation. Fractures were considered nonunion which did not unite after six months or that needed additional operation procedure to unite. In this study, the results of all the treated monteggia fracture dislocations were evaluated using Anderson et al. ${ }^{\text {[5] }}$ scoring system (Table 5). The result was graded as excellent / good when the union of the fracture, loss of flexion and extension at the wrist or elbow of less than $10^{\circ}$, and loss of pronation and supination of $<25 \%$. In a fair / satisfactory result, there was union of fracture, loss of flexion or extension at the wrist or elbow of less than $20^{\circ}$, and loss of pronation and supination of less than $50 \%$. The result was scored as bad when there was union of the fracture and either loss of flexion and extension at the wrist or elbow of more than $20^{\circ}$ or loss of pronation and supination of more than $50 \%$. A nonunion or unresolved chronic osteomyelitis was graded as failure.

\section{Results and Discussion}

In this study, male and female patients were in 5:1 ratio with male predominance of $83.33 \%$. The percentage of male predominance is slightly higher than the earlier observed results of Ring et al. ${ }^{[6]}$. In this study the incidence of injury of Type I was in $77.77 \%$ cases and $22.23 \%$ cases were of Type II and no cases of type III and Type IV fracture dislocation. Our findings are similar to the observations made by Henry et $a l^{[7]}$.

Complications found in the present series (Table 7), 5.50\% each of delayed union of ulna, myositis ossificans, non-union of ulna, mal-union of ulna, radial nerve palsy, re-dislocation of radial head, subluxation of radial head and infection. Similar observations were reported earlier by Reckling [4], Chapman et al ${ }^{[8]}$ and Ring et al ${ }^{[6,9]}$.

Fracture of the radial head as it collides with the capitellum while dislocating posteriorly is present in most cases, adding further complexity to the injury. Anterior Monteggia lesion has been reported with radial head and neck fractures in some series.

MFD has been classified according to the displacement of the head of radius and of the fractured ulnar fragments in extension (Type I), flexion (Type II) and Type III and IV. In extension type there is anterior dislocation of head of radius and anterior and angulation or over riding or comminution of ulna at fracture site. According to Watson Jones ${ }^{[10]}$, it is as common as $85-90 \%$, while Penrose ${ }^{[11]}$ found this type to be only in $30 \%$ cases. In this series, it was found to be $77 \%$ cases. Type of displacement of head of radius and at fracture site in ulna has not been described in literature.

Based on Bado's classification, study conducted by Henry et al. ${ }^{[7]}$ showed $79 \%$ cases of Type I, $12 \%$ Type II, 6\% Type III, and $3 \%$ cases of Type IV. Earlier studies reported $70 \%$ cases of Type I, $18 \%$ Type II, $12 \%$ of Type IV and no case belonging to Type III. In the present study, $77.77 \%$ of the fracture dislocations were of Type I, 22.23\% were of Type II, no case of Type III and Type IV.

Evans ${ }^{[12]}$ and Speed and Boyd ${ }^{[13]}$ suggested that the injury is due to direct trauma while Naylor ${ }^{[14]}$ attributed it to be due to direct trauma. They supported their statement by the fact that in majority of the cases comminuted fracture of ulna and the local signs of injury in the shape of bruises and contusions occur. In the present study, $55.55 \%$ of the cases gave history of direct injury. In this series, in $\mathrm{n}=8$ cases there was evidence of local injury in the shape of bruises and contusions and $n=2$ cases were of compound injury. These evidences were in favour that this injury is caused by direct trauma. In the other $44.45 \%$ of the cases, patients were not sure of mode of injury though few of them attributed to fall on outstretched hand. Hence, it is concluded that MFD can be caused by both direct and indirect trauma. As this injury is quite common in Africa, surgeons working there have experienced $60-70 \%$ cases and they all supported direct trauma theory.

In this series, $\mathrm{n}=15(83 \%)$ of the patients were brought to the hospital within a week. Some of the patients were treated by massage resulting in myositic ossificans, stiff elbow. Out of total $n=18$ cases, $n=11(61.11 \%)$ of the cases came from the urban area and most of them were medico-legal cases. This observation is not mentioned in the literature.

The radial head plays a key role in maintaining stability of the elbow joint. Unreduced dislocation of the radial head for more than 4 weeks is considered to be chronic. The factors like interval between injury and treatment, patient's age and the amount of joint incongruity plays an important role ${ }^{[15]}$. Hirayama et al. ${ }^{[16]}$ and Stoll et al. ${ }^{[17]}$ reported that reconstruction could be successfully achieved in children up to the age of 10 years and at least four years after the injury.

Monteggia fractures are rare, representing approximately $1 \%$ of all fractures and/or dislocations of the wrist and mid or proximal forearm ${ }^{[18]}$. The ulnar fracture is readily diagnosed but, the radial head dislocation is often missed ${ }^{[19]}$. The majority of radial head dislocations in children can be reduced with manipulation under general anesthesia but, if the diagnosis is made late, open reduction is commonly required. This may involve repair or reconstruction of the annular ligament to prevent recurrent dislocation. Impaired elbow function, degenerative arthritis, and nerve palsies can result from persistent radial head dislocation.

\section{Functional outcome}

In the analysis of functional outcome of the results of our treated monteggia fracture dislocations were evaluated using Anderson et al. ${ }^{[5]}$ scoring system (Table 5) taking the range of movement as the main criteria, after physiotherapy.

Table 5: Anderson's scoring system for functional outcome

\begin{tabular}{|c|c|c|c|}
\hline Results & Union & $\begin{array}{c}\text { Flexion / Extension } \\
\text { at elbow joint }\end{array}$ & $\begin{array}{c}\text { Supination and } \\
\text { pronation }\end{array}$ \\
\hline Good & Present & $<10^{\circ}$ loss & $<25 \%$ loss \\
\hline Fair & Present & $<20^{\circ}$ loss & $<50 \%$ loss \\
\hline Poor & Present & $>20^{\circ}$ loss & $>50 \%$ loss \\
\hline Failure & \multicolumn{2}{|c|}{ Nonunion with or without loss of motion } \\
\hline
\end{tabular}

The results of the functional outcome of our study series are presented in Table 6. Using Anderson et al. ${ }^{[5]}$ scoring system functional outcome of our study showed excellent/good results in $46.15 \%$ cases, fair and satisfactory results in $7.69 \%$ patients and bad results in $46.15 \%$ (Table 6).

The results of surgical treatment in fresh cases of our study showed good results in $62.50 \%$ cases, fair in $12.5 \%$ cases and 
bad results in $25 \%$ patients. Out $\mathrm{n}=3$ cases of conservative treatment, $\mathrm{n}=1(33 \%)$ cases showed good results and bad results were observed in $n=2(67 \%)$ cases. In this study, $n=$ 2 old cases treated surgically, two cases showed bad results. Ring et al. ${ }^{[6]}$ reported $37.5 \%$ excellent results, $43.75 \%$ satisfactory results, $8.5 \%$ unsatisfactory results and failure in $10.45 \%$ of cases with slight variations compared to the present study findings. In this study, patients treated surgically by open reduction and internal fixation method showed good union in less than 4 months (Figures 2 - 6).

The extension type is by far the most common and represents some $85-90 \%$ of all Monteggia fractures. The flexion type is reported to occur exclusively in adults, in whom it is almost as common as the extension fracture. Bohler [20], Evans [12] and Naylor ${ }^{[14]}$ recommended closed reduction treatment and claim that the vast majority of both extension and flexion fractures can be reduced by such manipulation. Smith [21], Speed and Boyd ${ }^{[13]}$, Watson-Jones ${ }^{[10]}$ and others, however, prefer open reduction, particularly in the treatment of extension fractures.

Table 6: Functional outcome of the present study results according to Anderson et al (1975) criteria

\begin{tabular}{|c|c|c|c|c|c|}
\hline Subjects & Good & Fair & Bad & $\begin{array}{c}\text { No follow- } \\
\text { up }\end{array}$ & $\begin{array}{c}\text { Under } \\
\text { follow-up }\end{array}$ \\
\hline No. of cases & 6 & 1 & 6 & 1 & 4 \\
\hline $\begin{array}{c}\text { Percentage } \\
(\%)\end{array}$ & 46.15 & 7.69 & 46.15 & - & - \\
\hline
\end{tabular}

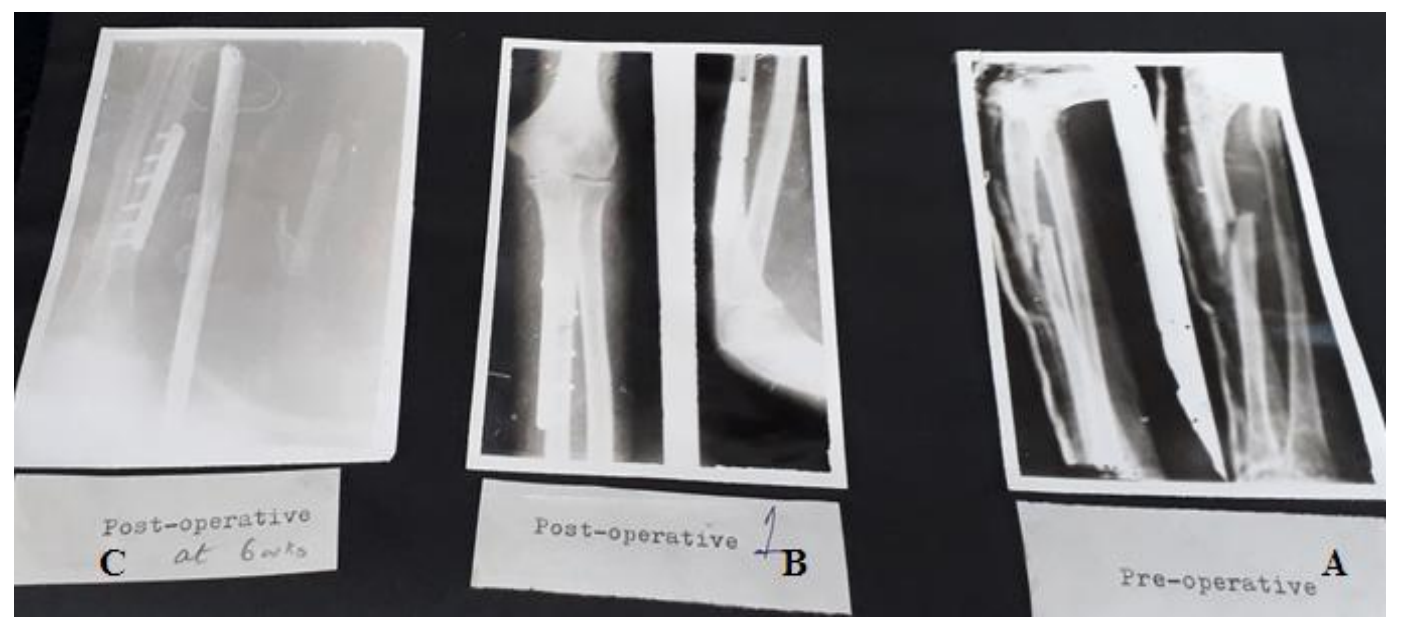

Fig 2: X-ray images: A- Pre-operative, B- post-operative, C- post-operative after 6 weeks

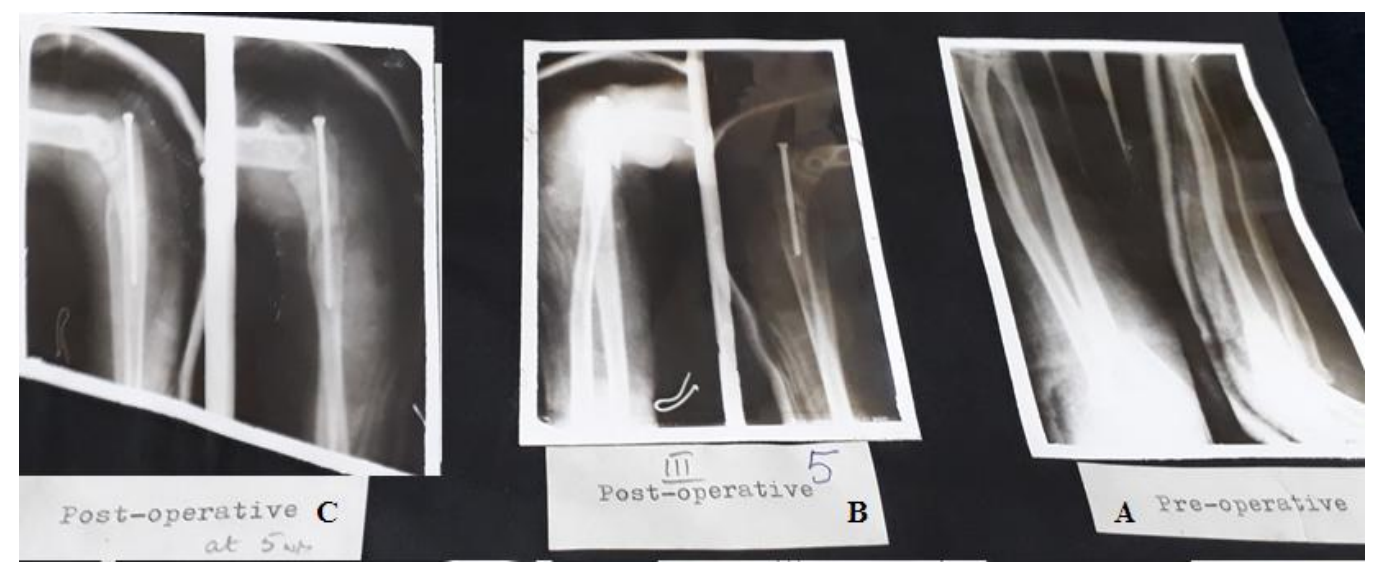

Fig 3: X-ray images: A- Pre-operative, B- post-operative, C- post-operative at 5 weeks

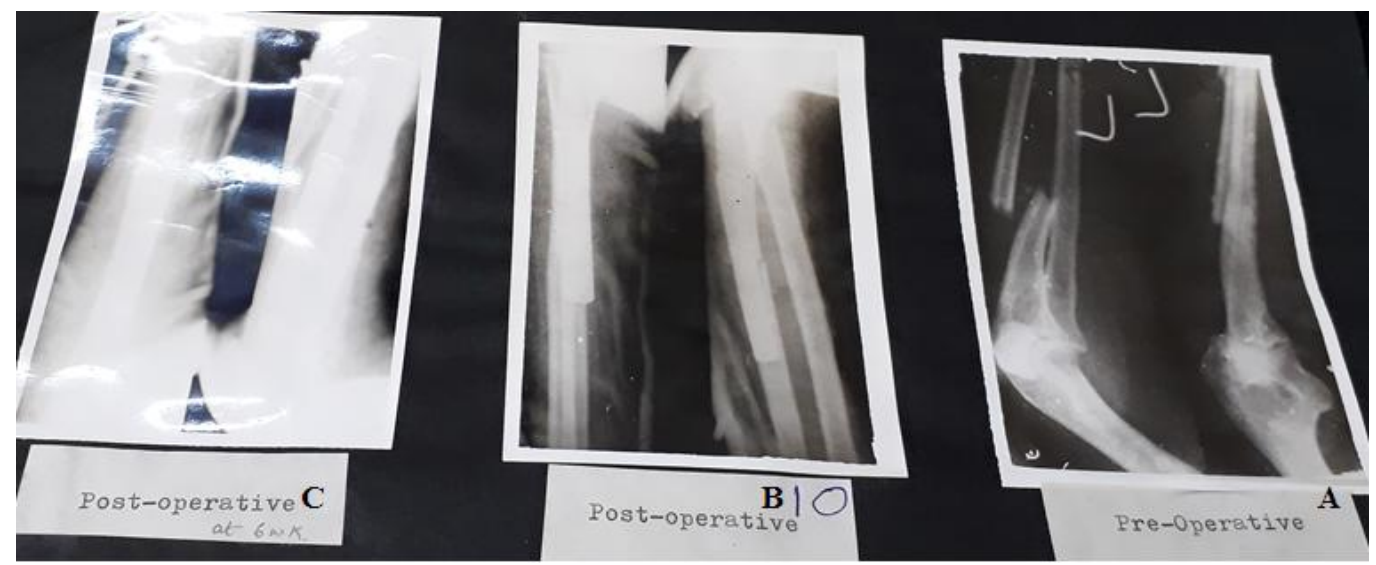

Fig 4: X-ray images: A- pre-operative, B- post-operative, C-post-operative at 6 weeks 

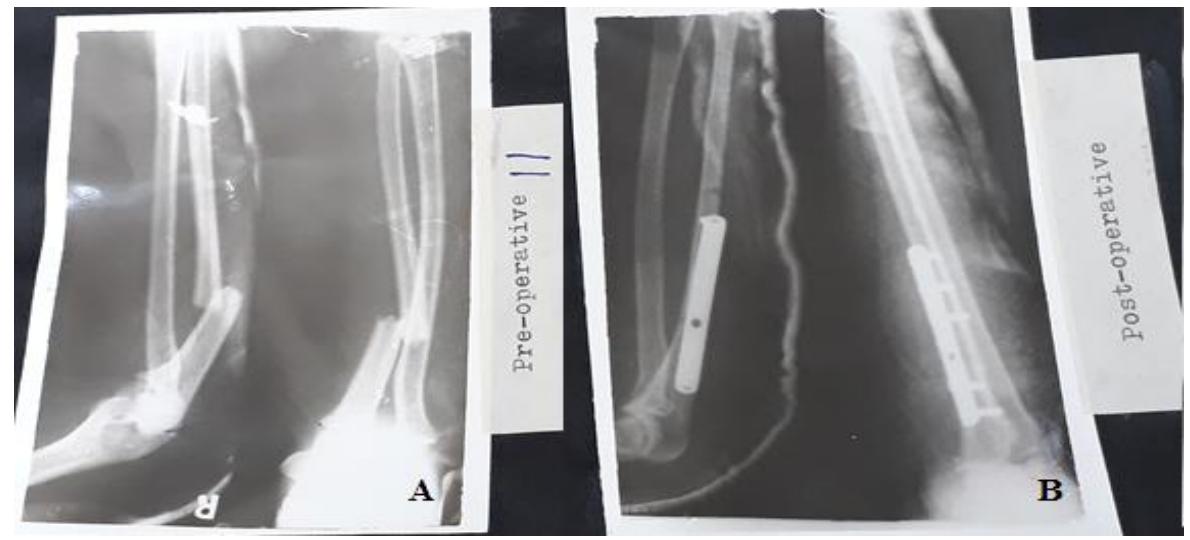

Fig 5: X-ray images: A- pre-operative, B- post-operative

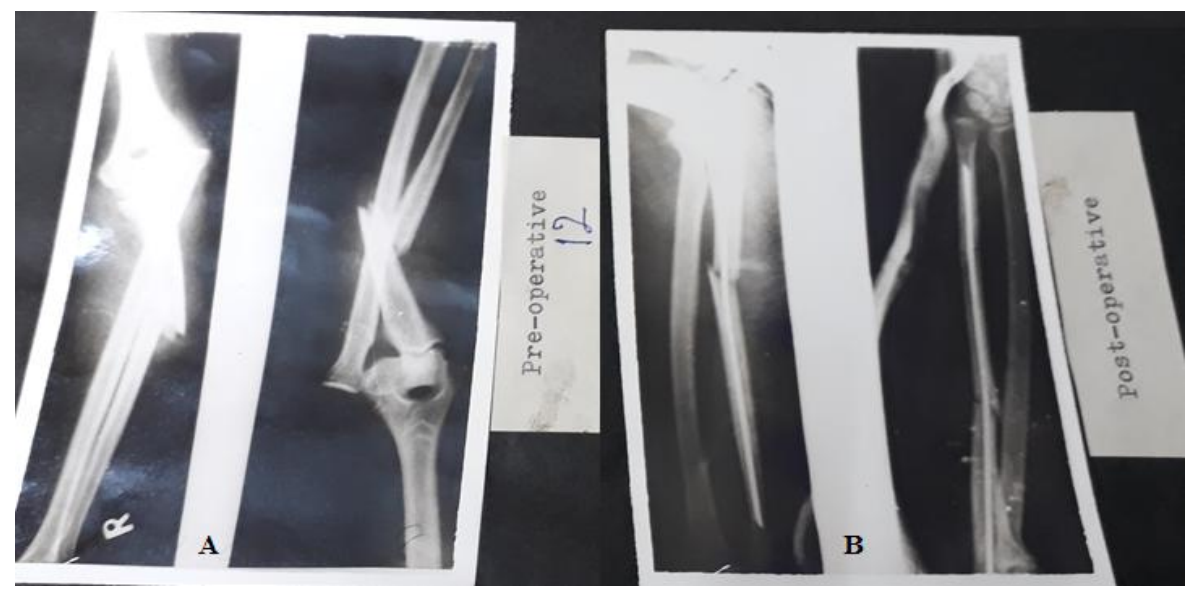

Fig 6: X-ray images: A- pre-operative, B- post-operative

\section{Complications}

Several complications like mal-union and non-union of ulna, un-reduced dislocation of radial head, subluxation of inferior radio-ulna joint, nerve injury, vascular disturbance and wound infection, etc., have been described from time to time by many workers from different parts of the world. Naylor ${ }^{[14]}$ in his series of 7 cases described fracture of radial head in one case. Speed and Boyd ${ }^{[13]}$ has mentioned re-dislocation of radial head. Complications found in present series are presented in Table 7. Delayed union of ulna $(n=1)$ was due to gross comminution and infection. Myositis ossificans observed in $n=1$ was due to massages. One $(n=1)$ patient developed mal-union of ulna which may be due to unstable nature of fracture and was the result of late displacement occurring in POP casing.

1 patient had radial nerve palsy which improved spontaneously; no surgical attempt was made to explore the nerve. 1 patient (boy) had re-dislocation of radial head in immediate post-operative period. In retrospect, it was unstable or probably not reduced. The child had fair range of movement but still the result has been graded as poor.

This injury may be treated either by closed reduction or by operative methods. In children closed reduction gives satisfactory results and offers good prognosis. Naylor [14] stated that though there is visible deformity yet function is good. Blount ${ }^{[22]}$ further supported these views that children having this injury for more than 3 months should be left alone as the result shall be quite satisfactory due to adaptation. Malgaigne ${ }^{[23]}$ also condemned the excision of radial head in children as this leads to cubitus valgus and later ulnar neuritis. In this series, 1 child treated surgically by closed reduction was successful. Treatment of acute fractures in adults is usually unsatisfactory by closed methods mainly because of unstable nature of the injury. Naylor ${ }^{[14]}$ could reduce successfully 2 out of 9 cases by closed methods. In our series of $n=18$ cases, closed reduction was performed in $n=12$ cases with satisfactory results in only $n=4$ cases. Watson Jones ${ }^{[10]}$ studied a consecutive series of 34 cases treated by many surgeons and mentioned good results only in 2 cases. Rest of the 32 cases had serious disabilities. $67 \%$ of our cases treated conservatively had bad result as compared to $62.5 \%$ good result in surgically treated cases. Thus, open reduction and internal fixation of fracture ulna is indicated in adults, and should be done as early as possible. The development of internal fixation has considerably improved the results in these fractures with early mobilization ${ }^{[6,9]}$. Closed reduction of radial head should be attempted, is often successful (72\%) if reduction of ulna was accurate. When a stable reduction is not obtained a portion of capsule is usually folded into the joint preventing complete reduction of the head. This fibrous structure should be removed and repair of annular ligament done. If annular ligament is damaged beyond repair, the fascial loop may be employed. We had this problem of radial head instability in three fresh cases. In $n=1$ case annular ligament was repaired and other case radial head excised. Radial head fracture should be treated surgically and one should be cautious that a bad fixation will result in delayed mobilization and re-surgeries as well as excision should be preferred in comminuted fractures.

Naylor ${ }^{[14]}$ advocated excision of radial head and internal fixation of ulna as the treatment of choice in old cases, this treatment has been supported by Speed and Boyd ${ }^{[13]}$. In this series, we had $n=2$ old injuries, $n=1$ had history of massages. Radial head was excised and ulna osteotomised and plating was done. In this study all the old cases had bad results. 
Table 7: Complications resulted in the present study subjects

\begin{tabular}{|c|c|c|c|}
\hline $\begin{array}{c}\text { S. } \\
\text { No }\end{array}$ & Complications & $\begin{array}{c}\text { No. of } \\
\text { cases }\end{array}$ & $\begin{array}{c}\text { Percentage } \\
(\mathbf{\%})\end{array}$ \\
\hline 1. & Myositis ossificans & 1 & 5.50 \\
\hline 2. & Delayed union of ulna & 1 & 5.50 \\
\hline 3. & Non-union of ulna & 1 & 5.50 \\
\hline 4. & Mal-union of ulna & 1 & 5.50 \\
\hline 5. & Re-dislocation of radial head & 1 & 5.50 \\
\hline 6. & Subluxation of radial head & 1 & 5.50 \\
\hline 7. & Infection & 1 & 5.50 \\
\hline 8. & Radial nerve palsy & 1 & 5.50 \\
\hline
\end{tabular}

\section{Conclusions}

The treatment of monteggia lesion in adults is usually unsatisfactory by closed methods. Hence, open reduction and internal fixation of ulna is the procedure of choice. The surgery should be done as early as possible. If the head of radius can be maintained by closed methods, surgical repair of annular ligament is not necessary. But, if the head is unstable or reduction is incomplete, the annular ligament should be explored and repaired. Closed reduction of acute fracture of ulna with dislocation of radial head may often be employed in children. For mal-union or non-union of ulna with dislocation of radial head, resection of head and neck of radius combined with bone grafting and plating of ulna is recommended. In children radial head should not be excised, as this leads to increasing cubitus valgus and late ulnar neuritis. The operative technique in these fractures is simplified and danger to radial nerve minimized by the single incision approach.

\section{References}

1. Monteggia GB. Lussazioni delle ossa delle estremita superiori. In: Monteggia GB., Editor. Instituzioni Chirurgiches. 2nd. Maspero; Milan, Italy. 1814; 5:131133.

2. Perrin J. Les fractures du cubitus accompagnees de luxation de l'extremite superieur du radius. In: Perrin J., Editor. These de Paris. G Steinheil, Paris, France, 1909.

3. Bado JL. The Monteggia lesion. Clin Orthop Relat Res. 1967; 50:71-86.

4. Reckling RH. Unstable fracture dislocations of the forearm (Monteggia and Galeazzi lesions). J Bone $\mathrm{Jt}$ Surg. 1982; 64-A:857-863.

5. Anderson LD, Sisk D, Tooms RE, Park WI. Compression plate fixation in acute diaphyseal fractures of the radius and ulna. J Bone Joint Surg Am. 1975; 57:287.

6. Ring D, Jupiter JB, Simpson NS. Monteggia fractures in adults. J Bone Joint Surg. Am. 1998a; 80A:1733-1744.

7. Henry EB, Paul JH, Wilson J. Monteggia fractures. J. Bone Joint Surg. 1974; 56-A:1563-1575.

8. Chapman, Michael W, Bruce A, Mallin, David TS. Fractures of the shaft of radius and ulna. In: Michael W, Chapman. Operative orthopaedics. 2nd Ed. Philadelphia, Lippincott. 1993; 1:489-502.

9. Ring D, Jupiter JB, Waters PM. Monteggia fractures in children and adults. J Am Acad Orthop Surg. 1998b; 6:215-224.

10. Watson-Jones R. Fractures and Joint Injuries. Fourth edition, Vol II. Edinburgh and London: E. \& S. Livingstone Ltd. 1956; 572.

11. Penrose JH. The Monteggia fracture with posterior dislocation of the radial head. J Bone Joint Surg Br. 1951; 33(1):65-73.

12. Evans EM. Pronation injuries of the forearm, with special reference to the anterior Monteggia fracture. J Bone Joint
Surg Br. 1949; 31B(4):578-588.

13. Speed JS, Boyd HB. Treatment of fractures of Ulna with dislocation of head of radius (Monteggia fracture). JAMA. 1940; 115(20):1699-1705.

14. Naylor A. Monteggia fractures. British J Surgery. 1942; 115(29):323-326.

15. Kim HT, Conjares JNV, Suh JT, Yoo IC. Chronic head dislocation in Children, Part 1: Pathologic changes preventing stable reduction and surgical correction. J Pediatr Orthop. 2001; 22:583-590.

16. Hirayama T, Takemitsu Y, Yagihara K, Mikita A. Operation for chronic dislocation of the radial head in children. Reduction by osteotomy of the ulna. J Bone Joint Surg Br. 1987; 69:639-642.

17. Stoll TM, Willis, Paterson DC. Treatment of the missed Monteggia fracture in the child. J Bone Joint Surg Br. 1992; 74:436-440.

18. Giustra PE, Killoran Pl, Furman RS, Root JA. The Missed Monteggia Fracture. Radiology. 1974; 110:45.

19. Dormans JP, Rang M. The problem of Monteggia fracture-dislocations in children. Orthopaedic clinics of North Amcerica. 1990; 21:251.

20. Bohler L. Technik der Knochenbruchbehandlung. Vienna. 1951.

21. Smith FM. Surgery of the Elbow. Springfield, 1954.

22. Blount WP. Fractures in children. Baltimore. Williams and Wilkins, 1955.

23. Malgaigne M. Revue medico-chirurgicale de Paris. XIII. Tome Quinzieme, Paris, France. 1854; 80:213-215. 